\title{
Conformational changes of U6 RNA during the spliceosome cycle: an intramolecular helix is essential both for initiating the U4-U6 interaction and for the first step of splicing
}

\author{
Thorsten Wolff and Albrecht Bindereif ${ }^{1}$ \\ Max-Planck-Institut für Molekulare Genetik, Otto-Warburg-Laboratorium, D-14195 Berlin (Dahlem), Germany.
}

\begin{abstract}
During each spliceosome cycle, U6 RNA undergoes several conformational changes, involving the formation and disruption of base-pairing interactions with U4 and U2 RNAs. By use of a mutational approach we have focused on the stem II region of U6, which can adopt alternative conformations: In the singular form of U6, it can form an intramolecular stem-loop structure; in the U4/U6 snRNP, the stem II region base-pairs with U4 RNA; in the active spliceosome, this region has been proposed to fold back into an intramolecular U6 helix in the context of a U6-U2 structure. Using chemical modification/interference assays and a mutational approach we found that the 3' terminal loop of the singular U6 (nucleotides 65-69) is essential for initiating the U4-U6 base-pairing interaction. A series of point mutations in the adjacent helix was designed to alter the stability of the intramolecular helix. Stabilizing mutations inhibited the formation of the U4/U6 snRNP. In contrast, mutant U6 RNAs with a destabilized intramolecular helix were still active in U4-U6 interaction and spliceosome assembly; however, their ability to support the first step of splicing was strongly reduced, suggesting that the intramolecular U6 helix has an important function in the first step of splicing. Affinity-purified U4 snRNP and U6 RNA did not assemble into a stable U4/U6 snRNP, unless complemented by nuclear extract, indicating that a protein factor (or factors) is necessary for the U4-U6 interaction. In sum, these data demonstrate that the stem II region of U6 functions both in U4-U6 interaction and in the first step of splicing; they also provide evidence that the balanced stability of different conformations of U6 RNA is critical for its function.
\end{abstract}

[Key Words: Splicing; spliceosome; U2; U6; snRNA; snRNP]

Received March 16, 1993; revised version accepted May 13, 1993.

Pre-mRNA splicing requires the assembly of the splicing substrate into a large ribonucleoprotein complex-the spliceosome. A large number of proteins and five small nuclear RNAs (U1, U2, U4, U5, and U6) collaborate as essential cofactors during the ordered assembly of the spliceosome and during splicing (for review, see Maniatis and Reed 1987; Green 1991; Guthrie 1991). The U1 and U2 small nuclear ribonucleoproteins (snRNPs) interact with the pre-mRNA through RNA base-pairing interactions with the $5^{\prime}$ splice site and the branchpoint region, respectively (for review, see Steitz et al. 1988). U6 RNA, which is the most conserved among the spliceosomal snRNAs, engages in multiple interactions with $\mathrm{U} 4$ and U5 before being incorporated into the spliceosome: Initially, U6 assembles with the U4 snRNP into the U4/U6 snRNP; the U4/U6 snRNP then interacts with the U5

${ }^{1}$ Corresponding author.
snRNP to give the U4/U5/U6 snRNP/Behrens and Lührmann 1991), which in mammalian splicing extract is the predominant snRNP complex of U6 and is considered to be the form in which U6 enters the spliceosome. Recent evidence demonstrates that in addition to $\mathrm{U} 1$ and $\mathrm{U} 2$ RNAs, U6 and U5 also directly contact the two splice site regions (Sawa and Shimura 1992; Wassarman and Steitz 1992; Wyatt et al. 1992; for review, see Steitz 1992).

For the singular forms of both U4 and U6, secondary structures have been proposed that differ considerably from the U4/U6 RNA hybrid (Harada et al. 1980; Rinke et al. 1985; Myslinski and Branlant 1991; see also Fig. 1). In the U4/U6 snRNP, U4 and U6 RNAs are held together stably by RNA base-pairing through the stem I and stem II regions, forming a phylogenetically highly conserved secondary structure, the so-called Y structure (Brow and Guthrie 1988; Guthrie and Patterson 1988). On the basis of a compensatory mutant study in the yeast Saccharo- 

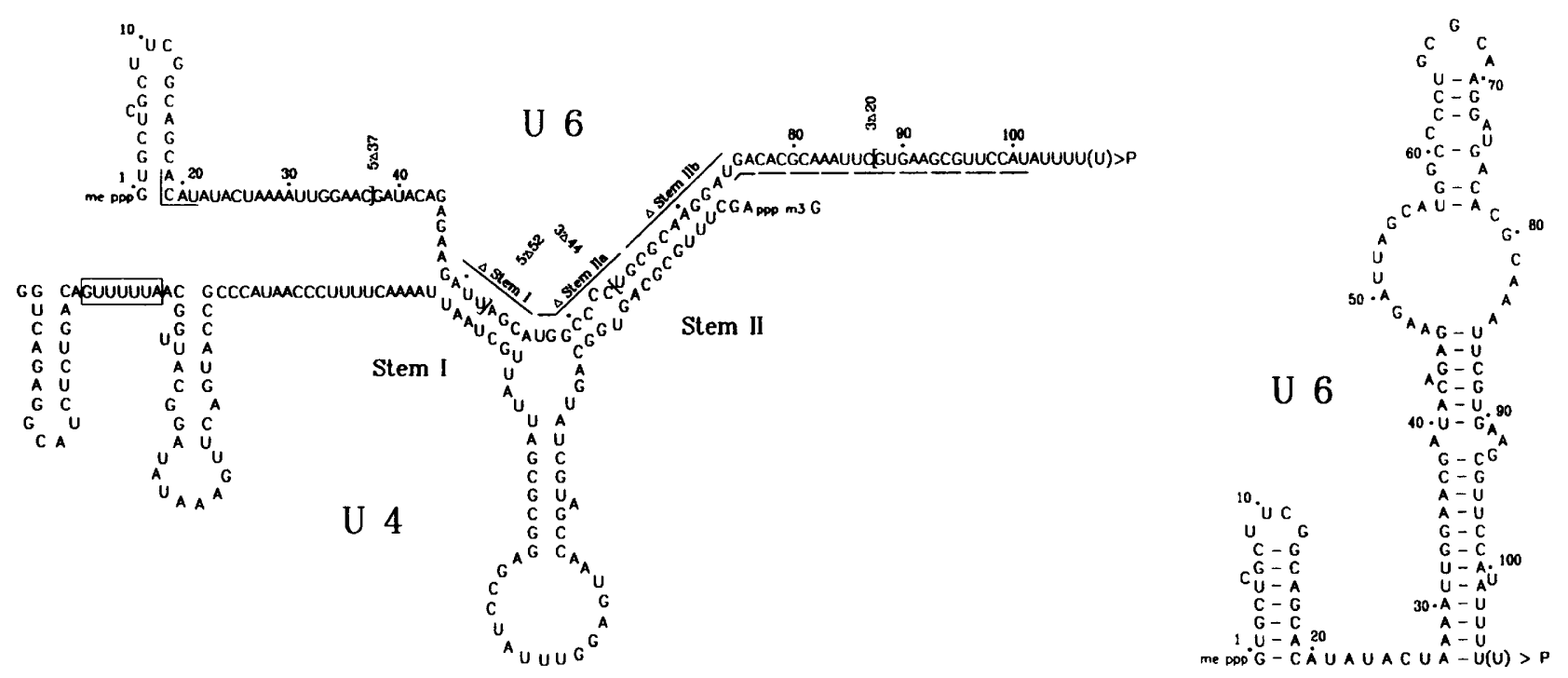

Figure 1. Secondary structure models of the singular form of human U6 RNA (Rinke et al. 1985) and of the human U4/U6 base-paired complex (Guthrie and Patterson 1988). The 5'-terminal, $3^{\prime}$-terminal, and internal deletions used in this study are indicated; the Sm-binding site of $\mathrm{U} 4$ is represented by a box.

myces cerevisiae, another conformational state of U6 RNA has recently been proposed, in which U6 interacts with U2 (Madhani and Guthrie 1992; see also Fig. 9, below): Base-pairing between the stem I of U6 and U2 (helix I) may allow the stem II region of U6 to refold into the same intramolecular helix present in the singular U6 form. This U6-U2 structure is mutually exclusive with the U4-U6 base-pairing and is therefore assumed to occur in the active spliceosome after U4 and U6 have dissociated. Mutations in either the U6 or the U2 portion of U6-U2 helix I result in first- or second-step splicing defects, underlining its splicing-essential nature /Madhani and Guthrie 1992; McPheeters and Abelson 1992; for review, see Weiner 1993). An additional U6-U2 basepairing interaction between a sequence near the $3^{\prime}$ end of U6 and the $5^{\prime}$ terminal sequence of U2 has also been established (Hausner et al. 1990; Watkins and Agabian 1991); in the mammalian system, this interaction has been demonstrated to be essential for splicing function (Datta and Weiner 1991; Wu and Manley 1991). Both U6-U2 interactions may occur simultaneously. Thus, the rearrangement of the U4-U6 into a U6-U2 structure would not only require the U4-U6 hybrid, but also the 5' terminal stem-loop of $\mathrm{U} 2$, to dissociate; accordingly, mutations increasing the stability of this stem-loop interfered with splicing (Wu and Manley 1992).

In sum, it has become clear that the ordered assembly, the functioning, and the disassembly of the spliceosome are dynamic processes involving alternative conformations and structural rearrangements of the participating snRNAs. Several lines of evidence based on mutational analyses in yeast (Fabrizio and Abelson 1990; Madhani et al. 1990; Madhani and Guthrie 1992) and on the discovery of mRNA-type introns within some fungal U6 RNA genes (Tani and Ohshima 1991) argue for a particularly important role of this RNA: U6 may be closely associ- ated with the catalytic center of the spliceosome (for review, see Guthrie 1991). In contrast, the U4 snRNP is not essential for the catalytic steps of the splicing reaction (Wersig and Bindereif 1992; Yean and Lin 1992); furthermore, dissociation of the U4-U6 RNA base-pairing occurs prior to or concomitantly with the appearance of splicing intermediates (Pikielny et al. 1986; Cheng and Abelson 1987; Konarska and Sharp 1987). These findings are consistent with the hypothesis that U4 functions primarily as an antisense regulator, keeping $\mathrm{U} 6$ in an inactive conformation during the initial stages of spliceosome assembly (Guthrie and Patterson 1988). The current model of spliceosome assembly and disassembly assumes that $\mathrm{U} 4$ is released from the spliceosome separately from U6; consequently, the U4/U6 snRNP must be reassembled to complete a cycle of conformational transitions.

On the basis of the evidence for a central role of U6 in splicing catalysis, a major current interest focuses on the role of conformational transitions of the U6 RNA during the spliceosome cycle. Whether and how protein factors are involved in this series of ordered rearrangements is still completely unclear. In yeast, a number of splicing factors with RNA helicase sequence motifs have been identified that are very good candidates for proteins regulating such RNA-RNA interactions (for review, see Guthrie 1991).

Recently, we have developed a splicing complementation assay to investigate the functions of U6 RNA at each stage of the spliceosome cycle: Purified U4 snRNP and U6 RNA are added back to U4/U6-depleted nuclear extract, thereby restoring splicing activity (Wolff and Bindereif 1992). In combination with a mutational approach, this allowed the mapping of several essential U6 sequence elements important for U4/U5/U6 multisnRNP and spliceosome assembly. Here, we report on a 
detailed mutational analysis of the U4-U6 interaction. We demonstrate that the initial interaction between the U4 snRNP and U6 RNA depends on additional protein factors in the extract. Through chemical modification/ interference assays we have obtained strong evidence that the initial U4-U6 contact is determined primarily by a short 3 '-terminal loop sequence present in the singular U6 RNA structure. Surprisingly, a class of point mutations in the adjacent intramolecular helix inhibits the first step of splicing, but not U4-U6 interaction nor spliceosome assembly. In sum, our data provide evidence that the intramolecular 3' stem-loop of U6 has a dual function in the splicing cycle: First, it is essential for the U4-U6 interaction, with the loop portion providing the initial U4-U6 base-pairing contact; second, the helix is essential for the first step of splicing. Our analysis also suggests that the balanced stability of different conformations of U6 RNA is critical for its function.

\section{Results}

\section{An assay system for the U4-U6 interaction}

Recently, we have developed an in vitro splicing complementation system for the functional analysis of mutant U6 RNAs (Wolff and Bindereif 1992). In brief, HeLa nuclear extract is first depleted of the U4/U6 snRNP through biotinylated antisense 2'-OMe RNA oligonucleotides and streptavidin-agarose (for the secondary structure of the U4/U6 RNA hybrid, see Fig. 1); affinity-purified U4 snRNP and U6 RNA are then added back, resulting in the efficient restoration of splicing activity. In this study we have used this system to characterize in detail the interaction between the U4 snRNP and U6 RNA or mutant derivatives thereof under conditions of splicing complementation. Affinity-purified U4 snRNP and ${ }^{32}$ P-labeled SP6-U6 RNA were incubated in U4/U6depleted nuclear extract under splicing conditions; ${ }^{32} \mathrm{P}$ labeled SP6-U6 stably associated with the U4 snRNP was recovered by coimmunoprecipitation with anti-Sm antiserum directed against the Sm proteins of the $\mathrm{U} 4$ snRNP, quantitated by Cerenkov counting (data not shown), and analyzed by denaturing gel electrophoresis (Fig. 2). The U4/U6 snRNP assembly proceeded relatively rapidly, reaching maximal levels of immunoprecipitation after $10 \mathrm{~min}$ (data not shown). Approximately $5 \%$ of wild-type SP6-U6 RNA was assembled into U4/ U6 snRNPs under standard conditions (lanes Ctr). As expected, this reaction depended on the addition of $\mathrm{U} 4$ snRNP (lanes labeled - U4), and no U6 RNA was precipitated by nonimmune serum (lane labeled Ctr, N). Although routinely carried out under splicing conditions, the reaction appears to be ATP independent (lanes labeled - ATP). Interestingly, the stable association of the U4 snRNP and U6 RNA in an Sm-precipitable complex occurred only in the presence of extract; if buffer was used instead of nuclear extract, no U4-U6 interaction could be detected by anti-Sm immunoprecipitation (lanes labeled buffer D), indicating that factors in addition to U4 snRNP and U6 RNA are required for the as-

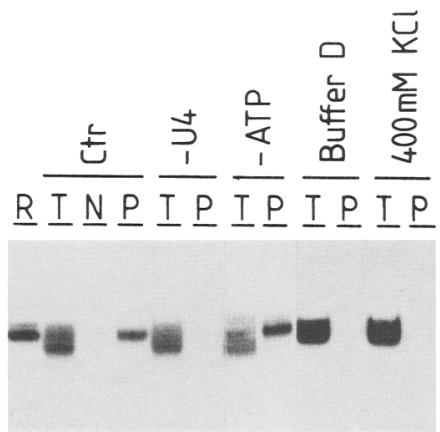

Figure 2. Assembly of a stable U4/U6 snRNP requires additional factor. Affinity-purified U4 snRNP and ${ }^{32}$ P-labeled SP6U6 RNA were incubated under standard conditions in U4/U6 depleted nuclear extract $(\mathrm{Ctr})$; control reactions were done in the absence of U4 snRNP (-U4), without the addition of ATP and creatine phosphate (-ATP), with buffer D instead of nuclear extract (Buffer D), and in U4/U6-depleted nuclear extract at $400 \mathrm{mM} \mathrm{KCl}(400 \mathrm{~mm} \mathrm{KCl})$. The assembly of a stable U4/U6 snRNP was assayed by anti-Sm immunoprecipitation [(lane $R$ ) SP6-U6 RNA; (lanes T) 10\% of the total reaction; (lane $N$ ) control immunoprecipitate with nonimmune serum; (lanes $P$ ) immunoprecipitate with anti-Sm antiserum].

sembly of a stable U4/U6 snRNP. Finally, no interaction occurred at $400 \mathrm{~mm} \mathrm{KCl}$ (lanes labeled $400 \mathrm{~mm} \mathrm{KCl}$ ).

\section{Mutational analysis of the U4-U6 interaction}

To characterize the sequence requirements of U4-U6 interaction, we first analyzed the effects of $5^{\prime}$ - and $3^{\prime}$-terminal and internal deletions on the ability of U6 RNA to assemble into a U4/U6 snRNP (Fig. 3A,B; for a schematic representation of the mutant U6 RNAs, see Fig. 1). Deleting the highly conserved ACAU sequence (nucleotides 18-21; Fig. 3A, lanes $\Delta 18-21$ ), which is important for efficient U6 RNA capping (Singh et al. 1991), nuclear transport (Hamm and Mattaj 1989), and protein binding (Gröning et al. 1991), did not reduce U4-U6 interaction; neither did deleting the first 37 nucleotides of SP6-U6 (lanes $5^{\prime} \Delta 37$ ). Even when the deletion extended 4 nucleotides into the stem I sequence, the efficiency of U4-U6 interaction was not reduced significantly (lanes $5^{\prime} \Delta 52$ ). An internal deletion of the entire stem I still allowed a significant level of U4/U6 snRNP assembly $(\sim 50 \%$ of wild-type SP6-U6), whereas two deletions within the stem II region abolished the activity completely (lanes $\Delta$ stem I, $\Delta$ stem IIa, and $\Delta$ stem IIb). In contrast to the 5 '-terminal deletions, deleting 20 or 44 nucleotides from the $3^{\prime}$ end resulted in very low or undetectable levels of U4-U6 interaction, respectively (lanes $3^{\prime} \Delta 20$ and $3^{\prime} \Delta 44$ ). To analyze the importance of the 3 '-terminal domain for U4-U6 interaction in more detail, a series of internal, 3or 4-nucleotide deletions spanning positions 74-101 was tested: Except for SP6-U6 $\Delta 96-98$, which was strongly reduced, all of these internal deletions had activities between $50 \%$ and $100 \%$ of wild-type SP6-U6 (Fig. 3B). In sum, these results indicate that the $5^{\prime}$-terminal and the 


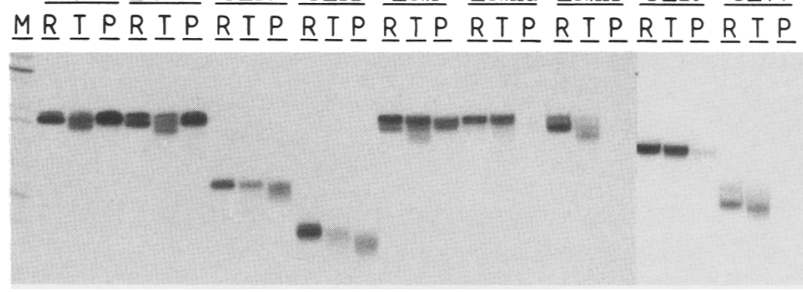

Figure 3. Assembly of human U6 RNA deletion derivatives and heterologous U6 RNAs into U4/U6 snRNPs. Affinity-purified U4 snRNP and ${ }^{32} \mathrm{P}-1 \mathrm{a}-$ beled mutant derivatives of SP6-U6 RNA were incubated under standard conditions in U4/U6-depleted nuclear extract, followed by immunoprecipitation assays with anti-Sm antiserum. (R) RNA; (T) $10 \%$ of the total reaction; $(\mathrm{P})$ anti-Sm immunoprecipitate); (M) ${ }^{32}$ P-labeled pBR322/HpaII fragments. The mutant derivatives of SP6-U6 RNA are indicated above the lanes [(WT) wild-type SP6-U6]: $(A)$ $5^{\prime}$ - and $3^{\prime}$-terminal deletions and internal deletions in the stem I/II region; $(B)$ internal deletions in the $3^{\prime}$ terminal domain; $(C)$ trypanosome and yeast U6 derivatives. Secondary structure models are given for the intramolecular $3^{\prime}$ stem-loops of yeast U6 (Madhani and Guthrie 1992), with the double mutation $\mathrm{A}_{73} \mathrm{G} \mathrm{U}_{74} \mathrm{C}$ in the yeast loop indicated, and trypanosome U6 $(T$. brucei sequence; alternative secondary structures are possible).
B

$\underline{W T} \Delta \frac{\Delta 74-76}{\Delta 77-79} \Delta 80-82 \Delta 83-85 \Delta 886-89 \Delta 90-92 \Delta 93-95 \Delta 96-98 \Delta \Delta 99-101$ M $\underline{R} I \underline{P} \underline{R} I \underline{P} \underline{R} I \underline{P} \underline{R} I \underline{P} \underline{R} I \underline{P} \underline{R} I \underline{P} \underline{R} I \underline{P} \underline{R} I \underline{P} \underline{R} I \underline{P} \underline{R} I \underline{P}$ -

C

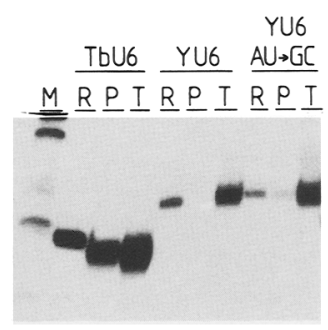

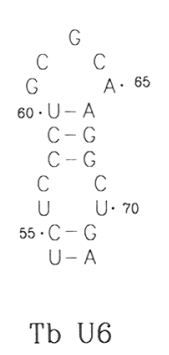

central domains of U6 are dispensable for U4/U6 snRNP assembly. Stem II of the U4-U6 interaction domain, however, is essential for the U4/U6 snRNP assembly; optimal activity requires stem I and the integrity of the $3^{\prime}$-terminal domain in addition.

Because U6 RNA has been highly conserved in evolution, we also tested two heterologous U6 RNAs from Trypanosoma brucei and the yeast $S$. cerevisiae for their ability to interact with the human U4 snRNP in mammalian extract (Fig. 3C; the $3^{\prime}$-terminal stem-loops of singular structure models for yeast and trypanosome U6 RNA are shown; see below). Surprisingly, the trypanosomal U6 RNA interacted efficiently with the human U4 snRNP, whereas the yeast U6 RNA showed no activity (lanes TbU6 and YU6). The stem II sequence from trypanosome $\mathrm{U} 6$ is identical with the human sequence except for the first two positions (nucleotides $\mathrm{C}_{55} \mathrm{U}_{56}$ of T. brucei U6 RNA). In contrast, the two mismatches between the yeast and human 3 '-terminal loops (nucleotides $\mathrm{A}_{73} \mathrm{U}_{74}$ of $S$. cerevisiae U6 RNA) would create unpaired positions in the middle of the potential human U4/yeast U6 stem II. This might explain why the heterologous human U4/yeast U6 interaction did not work. To test this hypothesis, two point mutations were introduced into the yeast $U 6$ RNA sequence $\left(A_{73} G U_{74} C\right)$ that should allow the heterologous human $\mathrm{U} 4$ / yeast $\mathrm{U} 6$ basepairing in stem II: In fact, U4-U6 interaction activity was regained, although at a relatively low level (lane YU6 $A_{73} G U_{74} \mathrm{Cl}$. In sum, these results emphasize the importance of the stem II sequence for U4-U6 interac- tion; although it is not sufficient by itself for efficient U4/U6 snRNP assembly, it is clearly essential.

\section{Chemical modification/interference analysis of the U4-U6 interaction}

We then used chemical modification/interference assays (Peattie 1979; for review, see Conway and Wickens 1989) to identify U6 nucleotides critical for U4-U6 interaction. $3^{\prime}-{ }^{32}$ P-End-labeled SP6-U6 RNA was chemically modified with diethylpyrocarbonate (DEPC) or hydrazine. DEPC modifies purines by N7-carbethoxylation (under our conditions, adenosines reacted preferentially over guanosines), and hydrazine modifies pyrimidines (depending on the reaction conditions, resulting in base removal of uridines or cytosines). 3'-End-labeled, chemically modified SP6-U6 RNA $(A>G, C, U)$ was then incubated with affinity-purified U4 snRNP in U4/U6depleted nuclear extract. Reconstituted U4/U6 snRNPs were purified by immunoprecipitation with anti-Sm antibodies, and immunoprecipitated U6 RNA was cleaved with aniline and analyzed by denaturing gel electrophoresis (Fig. 4). The cleavage pattern of modified free U6 RNA gives the U6 RNA sequence pattern as a reference (lanes RNA, A $>G ; U ; C$ ). U6 nucleotides essential for the U4-U6 interaction were identified by comparing the cleavage patterns obtained with U6 RNA from the total reconstitution reaction (lanes labeled Total) and U6 RNA present in U4/U6 snRNPs (lanes labeled U4/U6). The interference effects are summarized within the pro- 


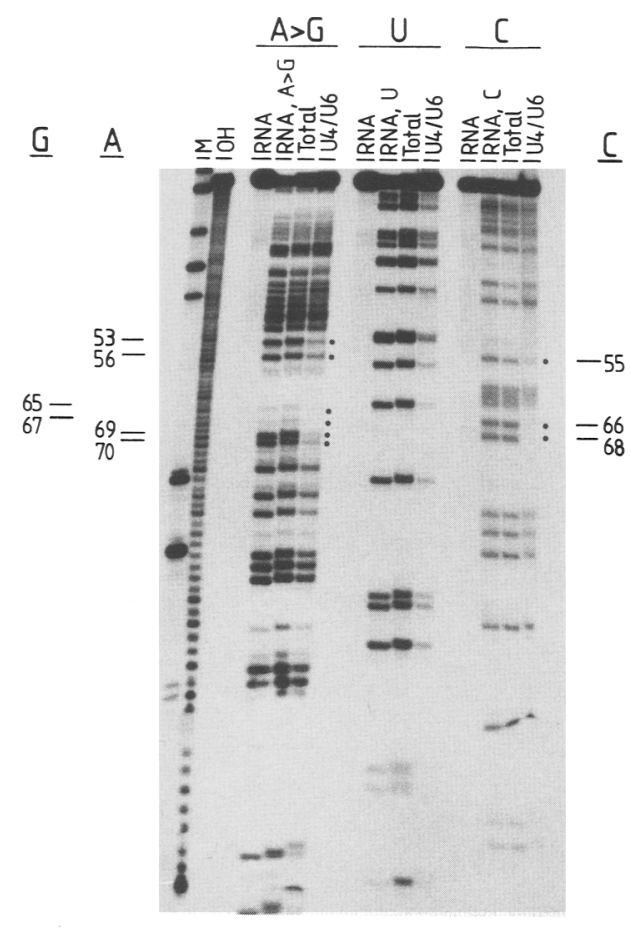

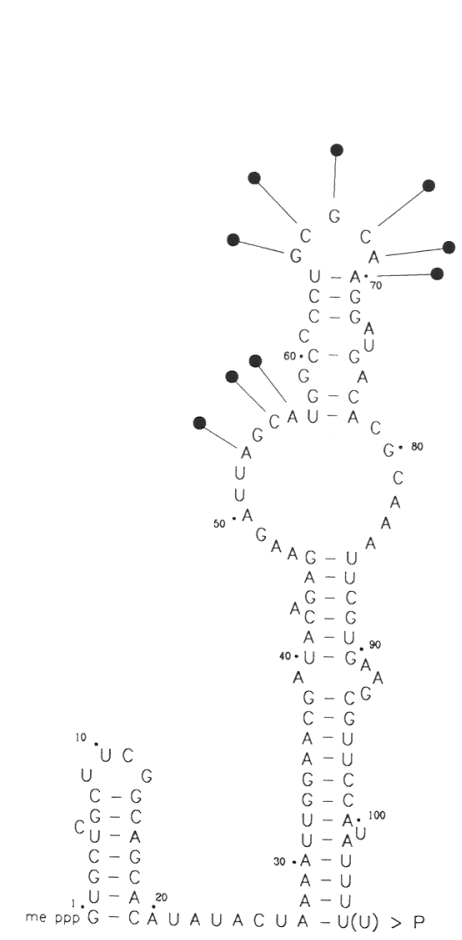

Figure 4. Chemical modification/interference analysis of U4/U6 snRNP assembly. $3^{\prime}-{ }^{32} \mathrm{P}$-End-labeled SP6-U6 RNA was chemically modified by DEPC $(\mathrm{A}>\mathrm{G})$ and hydrazine ( $\mathrm{U}$ or $\mathrm{C})$ and assembled with affinity-purified U4 snRNP into U4/U6 snRNPs. U6 RNA present in U4/U6 snRNPs was selected by anti-Sm immunoprecipitation, purified, and cleaved at the sites of modification by aniline. The cleavage patterns were analyzed by denaturing gel electrophoresis. Comparison of the cleavage patterns of modified U6 RNA obtained from the total reconstitution reaction (Total) and recovered from reconstituted $\mathrm{U} 4 /$ U6 snRNPs (U4/U6) identifies nucleotide positions in $\mathrm{U} 6$ that are essential for the U4-U6 interaction (marked by dots next to the U4/U6 lanes and indicated at right and left). In addition, modified RNAs without reconstitution either before (lanes RNA) or after aniline cleavage (lanes RNA, A > G; RNA, U; RNA, C) are shown. To the right, the interference data are summarized in the singular U6 RNA structure (Rinke et al. 1985). (O) Interference effects. posed singular U6 structure (Fig. 4). Strong interference effects clustered in nucleotides $G_{65}$ to $A_{70}$ in addition, weak interference was detected for $A_{53}, C_{55}$, and $A_{56}$. We note that because of the nature of the modification reaction the sensitivity of detecting interference effects at guanosine positions is relatively low. Significantly, interference was observed for all five positions of the loop sequence (nucleotides 65-69) of the 3'-terminal stemloop in the singular U6 structure (Harada et al. 1980; Rinke et al. 1985). In the U4/U6 hybrid, these positions are located in the middle of stem II; the weakly interfering positions 53,55, and 56 reside in stem I (cf. with Fig. 1). Taken together, the interference analysis therefore suggests that U4-U6 interaction initiates with a basepairing contact of the U6 3 '-terminal loop with the U4 RNA, followed by a more extensive rearrangement of $\mathrm{U} 4$ and U6 to the fully base-paired U4-U6 structure.

\section{Stabilizing or destabilizing mutations identify functions of an intramolecular helix of U6 RNA both in U4-U6 interaction and in splicing}

U6 assembly into the U4/U6 snRNP is accompanied by a major structural transition of U6 RNA: In the proposed singular U6 structure, nucleotides $57-78$ form an intramolecular stem-loop, which has to dissociate before the stem II base-pairing interaction with $\mathrm{U} 4$ can take place. In the U4/U6 snRNP, U4 and U6 RNAs are stably base-paired with each other through stem I and stem II. In the active spliceosome, another major conformational transition has been proposed, in that the U4-U6 basepairing is disrupted, followed by formation of a U6-U2 interaction; in this context, the original intramolecular
U6 helix (nucleotides 57-78) may reform (Madhani and Guthrie 1992; see Fig. 9, below). To study these conformational changes in more detail, we designed two series of U6 mutations within the stem II region that should either stabilize or destabilize the intramolecular U6 helix; at the same time, these mutations should have minimal effects on U4-U6 helix stability (Fig. 5; for a summary, see Table 1). All of these mutations were introduced into wild-type T7-U6, which-in contrast to SP6U6 used previously as transcriptional template (Bindereif et al. 1990) - carries no extra nucleotides at the ends. T7-U6 and SP6-U6 RNAs are similarly active in splicing complementation; T7-U6 RNA and its mutant de-

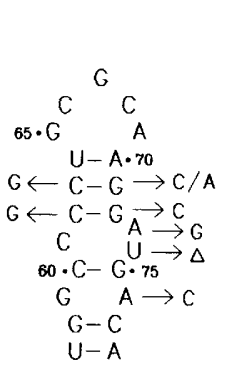

U6 3' Stem-loop

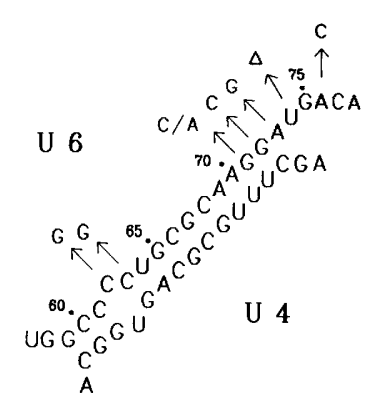

Stem II
Figure 5. Schematic representation of the two conformations of the stem II region of human U6 RNA: Intramolecular U6 $3^{\prime}$ stem-loop (to the left) and U4-U6 base-paired stem II (to the right). Shown are nucleotides 57-78 of human U6 RNA and nucleotides $1-16$ of human U4 RNA, with all point mutations indicated within both conformations. 
Table 1. U4-U6 interaction, spliceosome assembly, and splicing activities of human U6 RNA derivatives with mutations in the intramolecular helix

\begin{tabular}{|c|c|c|c|c|c|}
\hline \multirow[b]{2}{*}{ Mutation } & \multicolumn{2}{|c|}{ Stability } & \multirow{2}{*}{$\begin{array}{c}\text { U4-U6 } \\
\text { interaction }\end{array}$} & \multirow{2}{*}{$\begin{array}{l}\text { Spliceosome } \\
\text { assembly }\end{array}$} & \multirow[b]{2}{*}{ Splicing } \\
\hline & U6 & U4-U6 & & & \\
\hline T7-U6 wild-type & 0 & 0 & ++ & ++ & ++ \\
\hline $\mathrm{A}_{73} \mathrm{G}$ & + & 0 & $+1-$ & $+1-$ & + \\
\hline $\mathrm{A}_{73} \mathrm{G} \Delta \mathrm{U}_{74}$ & + & 0 & - & - & - \\
\hline $\mathrm{A}_{73} \mathrm{G} \Delta \mathrm{U}_{74} \mathrm{~A}_{76} \mathrm{C}$ & + & 0 & - & - & - \\
\hline $\mathrm{C}_{62} \mathrm{G}$ & - & + & ++ & ++ & $+1-$ \\
\hline$G_{71} A$ & - & + & ++ & ++ & + \\
\hline $\mathrm{C}_{62} \mathrm{GG}_{71} \mathrm{~A}$ & - & + & ++ & $+t$ & - \\
\hline $\mathrm{C}_{63} \mathrm{G}$ & - & - & ++ & ++ & - \\
\hline $\mathrm{G}_{71} \mathrm{C}$ & - & - & ++ & ++ & $+1-$ \\
\hline $\mathrm{C}_{63} \mathrm{G} \mathrm{G}_{71} \mathrm{C}$ & 0 & - & $+1-$ & $+1-$ & - \\
\hline $\mathrm{G}_{72} \mathrm{C}$ & - & - & ++ & ++ & $+1-$ \\
\hline $\mathrm{C}_{62} \mathrm{G} \mathrm{G}_{72} \mathrm{C}$ & 0 & - & ++ & ++ & + \\
\hline
\end{tabular}

The activities of all U6 mutant derivatives in U4-U6 interaction, spliceosome assembly, and splicing are listed, together with the expected stabilities of the U6 intramolecular helix and the U4-U6 stem II. The efficiencies are compared with those of wild-type T7-U6 and expressed as $++|50-100 \%|,+(10-50 \%),+/-\mid<10 \%$, but above background level), and - (background level). The stabilities of the intramolecular U6 helix (nucleotides 57-78; U6) and the U4-U6 stem II structure (U4-U6) are estimated for the mutant U6 RNAs on the basis of their base-pairing potential [see Fig. 5; $(0)$ neutral; $|+|$ stabilized; $(-)$ destabilized].

rivatives have comparable stabilities in extract (see below and data not shown). For the U4-U6 interaction and spliceosome assembly assays described below, T7-transcribed RNAs were labeled with RNA ligase and ${ }^{32} \mathrm{P}-$ labeled $\mathrm{pCp}$, because they were incorporated at higher efficiencies and resulted in clearer signals than when internally labeled RNAs were used. The assembly of ${ }^{32} \mathrm{P}$ labeled U6 RNAs into U4/U6 snRNPs and spliceosomes was tested under in vitro splicing complementation conditions; spliceosome assembly was assayed by native gel electrophoresis to visualize the heparin-resistant B-type splicing complex containing U2, U4, U5, and U6 RNAs (Konarska and Sharp 1987); splicing function was determined by in vitro complementation /see Materials and methods).

Initially, a set of three mutant derivatives with stemloops of increasing stability were constructed (see Fig. 5; Table 1). First, in T7-U6 $A_{73} G$, the unpaired position $A_{73}$ was changed to $G$, thereby allowing a new base pair to form $\left(C_{61}-G_{73}\right)$ and extending the intramolecular helix from 3 to $4 \mathrm{bp}$; second, in T7-U6 $\mathrm{A}_{73} \mathrm{G} \Delta \mathrm{U}_{74}$, the bulge position $U_{74}$ was deleted in addition, extending the upper helix to five consecutive base pairs; third, in T7-U6 $\mathrm{A}_{73} \mathrm{G} \Delta \mathrm{U}_{74} \mathrm{~A}_{76} \mathrm{C}$, another unpaired position, $\mathrm{A}_{76}$, has been mutated to $\mathrm{C}$, which should allow base-pairing with $\mathrm{G}_{59}$ and extend the helix to $8 \mathrm{bp}$. Whereas these mutations are expected to stabilize the intramolecular U6 stem-loop to different extents, they should have no effect on the stability of the U4-U6 stem II because they lie outside of the U4-U6 base-pairing region (Fig. 5). These U6 mutant derivatives were analyzed for their U4-U6 interaction, spliceosome assembly, and splicing complementation properties (Figs. 6, 7, and 8, respectively; for a summary, see Table 1): Surprisingly, the mutation with the smallest predicted stabilizing effect
(T7-U6 $A_{73} G$ ) resulted in a strongly reduced U4-U6 interaction; spliceosome assembly was similarly low, and splicing activity was reduced. Both mutant derivatives with intramolecular stem-loops of further increased stability (T7-U6 $A_{73} G \Delta U_{74}$ and T7-U6 $A_{73} G \Delta U_{74} A_{76} C$ ) reduced U4-U6 interaction and the other activities to levels below the limit of detection. In the case of these three mutant U6 RNAs, we observed reproducibly that less RNA migrated in the lower half of the spliceosome assembly gel than seen with wild-type U6 RNA and other mutant derivatives (Fig. 7 and data not shown). For unknown reasons, the T7-U6 $\mathrm{A}_{73} \mathrm{G} \Delta \mathrm{U}_{74} \mathrm{~A}_{76} \mathrm{C}$ RNA consistently migrated somewhat more slowly than wildtype U6 RNA during denaturing gel electrophoresis (Fig. 6 , lane $A_{73} G \Delta U_{74} A_{76} C_{\text {; }}$ data not shown). In sum, the

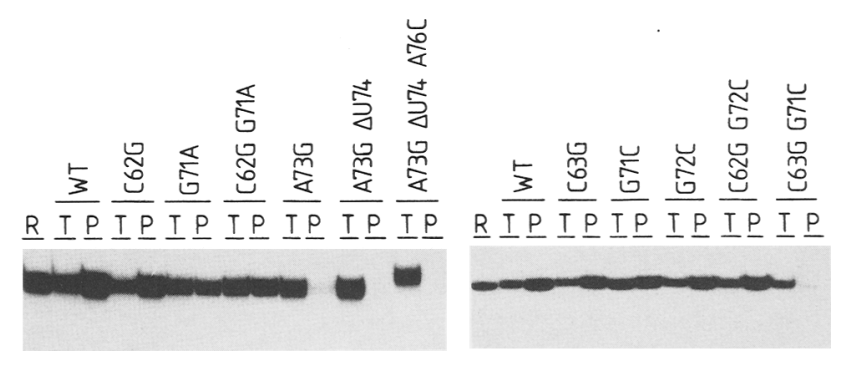

Figure 6. U4/U6 snRNP assembly of U6 RNAs with point mutations in the intramolecular helix. Affinity-purified $U 4$ snRNP and ${ }^{32}$ P-labeled U6 RNA derivatives were incubated under standard conditions in U4/U6-depleted nuclear extract, followed by immunoprecipitation with anti-Sm antiserum $[(\mathrm{T})$ $10 \%$ of the total reaction; $(\mathrm{P})$ anti-Sm immunoprecipitate]. The mutations are indicated above the lanes [(WT) wild-type T7U6]. (R) T7--U6 RNA. 


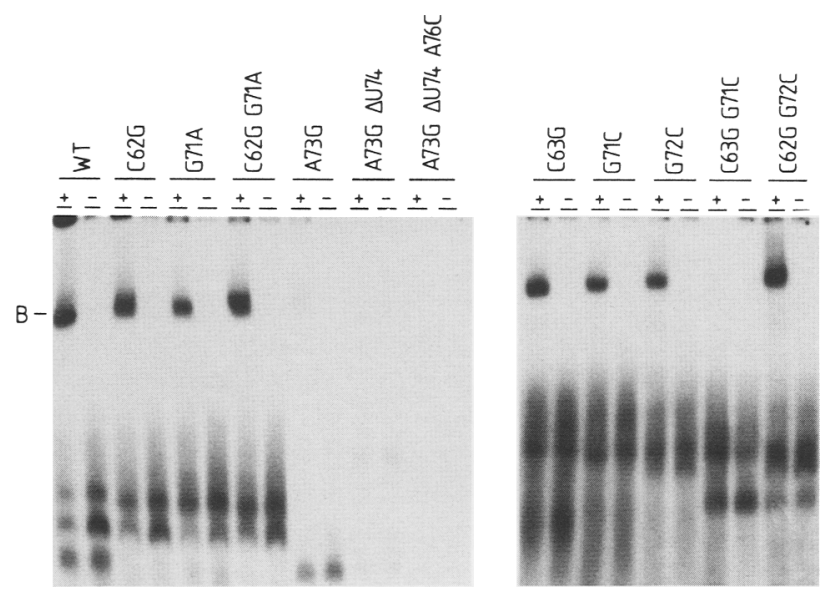

Figure 7. Spliceosome assembly of U6 RNAs with point mutations in the intramolecular helix. ${ }^{32}$ P-Labeled U6 RNA derivatives were incubated for 40 min under splicing complementation conditions with affinity-purified U4 snRNP and splicing substrate in U4/U6-depleted nuclear extract. The assembly of ${ }^{32}$ P-labeled U6 RNA derivatives into B-type spliceosomes was assayed by analysis through native gel electrophoresis. The mutations are indicated above the lanes [(WT) wild-type T7-U6]. For each U6 RNA, spliceosome assembly was assayed in the presence $(+)$ and absence $(-)$ of unlabeled splicing substrate. The position of the $\mathrm{B}$ complex, as derived from a control splicing reaction with ${ }^{32} \mathrm{P}$-labeled pre-mRNA (data not shown), is shown at left.
U4-U6 interaction could be inhibited by selectively stabilizing the intramolecular U6 helix. These results are entirely consistent with the secondary structure proposed for the singular U6, particularly with the upper part of the 3 '-terminal stem-loop (nucleotides 57-78); they also suggest that the balanced stabilities between the U6 and the U4-U6 conformations are critical for the U4/U6 snRNP assembly reaction.

We sought additional support for this conclusion by introducing a second series of mutations into U6 that should lead to a destabilization of the intramolecular U6 stem-loop (Fig. 5; Table 1): First, in T7-U6 $\mathrm{C}_{62} \mathrm{G}$, the third base pair $\left(\mathrm{C}_{62}-\mathrm{G}_{72}\right)$ from the top of the intramolecular helix has been disrupted; second, in T7-U6 $\mathrm{G}_{71} \mathrm{~A}$, the middle base pair $\left(C_{63}-G_{71}\right)$ has been disrupted; third, in T7-U6 $C_{62} G G_{71} A$, these two point mutations were combined. Besides destabilizing the singular U6 structure, these mutations should also have a slightly stabilizing effect on the U4-U6 stem II. Specifically, the two single-point mutations, $\mathrm{C}_{62} \mathrm{G}$ and $\mathrm{G}_{71} \mathrm{~A}$, convert a $\mathrm{C}-\mathrm{U}$ mismatch in the U4-U6 stem II into a G-U base pair and a $G-U$ into an A-U base pair, respectively. Each of these three mutant derivatives was tested in U4-U6 interaction, spliceosome assembly, and splicing assays (Figs. 6-8). They did not differ significantly from wild-type T7-U6 in their ability to form U4/U6 snRNPs (Fig. 6) and their assembly into spliceosomes (Fig. 7). Splicing complementation assays, however, revealed a remarkable effect of these mutations (Fig. 8): U6 RNAs with either of the two single point mutations $\mathrm{C}_{62} \mathrm{G}$ or $\mathrm{G}_{71} \mathrm{~A}$

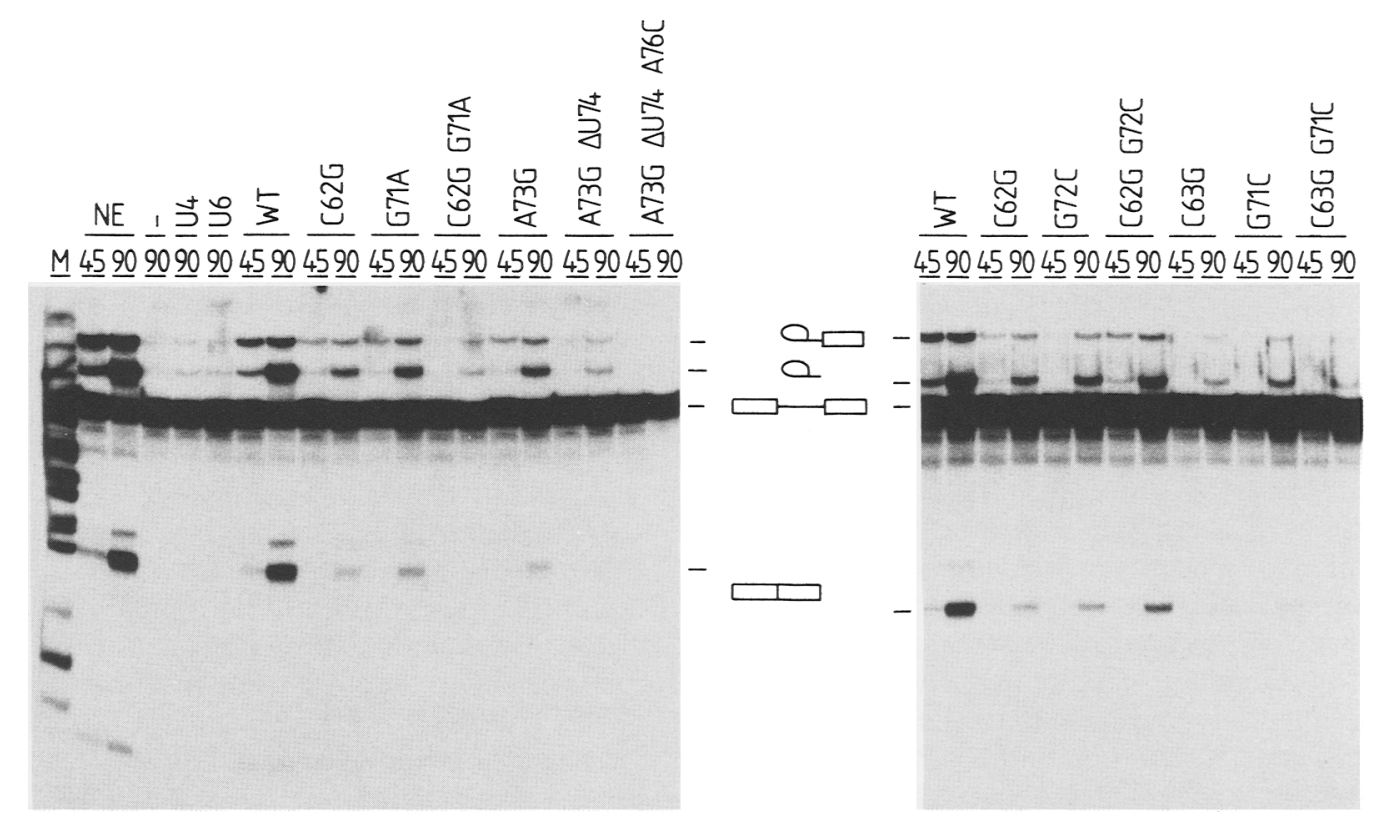

Figure 8. Splicing complementation activities of U6 RNAs with point mutations in the intramolecular helix. Unlabeled U6 RNA derivatives were incubated under splicing complementation conditions with affinity-purified U4 snRNP and ${ }^{32} \mathrm{P}$-labeled splicing substrate in U4/U6-depleted nuclear extract. Complementation of splicing activity after 45 and 90 min was assayed by RNA analysis through denaturing gel electrophoresis. The mutations are indicated above the lanes [(WT) wild-type T7-U6]. In control reactions, mock-treated nuclear extract (NE) was used, or splicing activity in U4/U6-depleted nuclear extract was tested without U4 and U6 (-), with $U 4$ snRNP alone (U4), and with U6 alone (U6). The positions of pre-mRNA, splicing intermediates, and products are indicated between the two panels. $(\mathrm{M})^{32} \mathrm{P}$-labeled pBR322/HpaII fragments. 
showed very low or reduced splicing activities, respectively, and no splicing activity above background was detected for the 2-nucleotide substitution $\mathrm{C}_{62} \mathrm{G} \mathrm{G}_{71} \mathrm{~A}$. These data demonstrate that there are specific requirements for splicing activity in the stem II region of U6 at a stage beyond spliceosome assembly. The effects of point mutations on splicing activity may reflect specific sequence requirements in this region. Because there is a correlation between the severity of the splicing defects and the altered stabilities of the two U6 conformations, however, the splicing defects are more likely the result of disturbing the balance between alternating U6 conformations, possibly between the U4-U6 and the U6-U2 structure. Two different effects have to be taken into account: First, the increased stability of the U4-U6 basepairing interaction might block U4-U6 unwinding in the spliceosome; second, the intramolecular U6 helix may not be stable enough to reform within the spliceosomal U6-U2 structure. As U4-U6 unwinding and formation of the U6-U2 conformation may very well be coupled, a combination of both of these effects may contribute to the observed splicing defects.

To distinguish between these two effects, a third set of five U6 derivatives with mutations in the intramolecular U6 helix was constructed. In contrast to the previous mutant sets, three single point mutations, $\mathrm{C}_{63} \mathrm{G}, \mathrm{G}_{71} \mathrm{C}$, and $\mathrm{G}_{72} \mathrm{C}$, should destabilize both the intramolecular helix of U6 and the U4-U6 base-paired structure (Fig. 5; Table 1). In two compensatory double mutations, $\mathrm{C}_{63} \mathrm{G}$ $G_{71} C$ and $C_{62} G G_{72} C$, the two positions of either the second or the third base pair from the top of the U6 helix have been inverted; the stability of the intramolecular helix should therefore be very similar to that of wildtype U6, whereas the U4-U6 interaction is expected to be destabilized.

The analysis of these five mutant U6 RNAs in the U4-U6 interaction assay showed that with the exception of one mutant RNA, $\mathrm{C}_{63} \mathrm{G} \mathrm{G}_{71} \mathrm{C}$, all were assembled into stable U4/U6 snRNPs at efficiencies similar to wild type (Fig. 6). These mutant derivatives also assembled into spliceosomes at wild-type efficiency, except for $\mathrm{C}_{63} \mathrm{G}$ $\mathrm{G}_{71} \mathrm{C}$, which exhibited only very low incorporation, most likely because of its U4/U6 snRNP assembly defect (Fig. 7). Finally, splicing activities for all five mutant derivatives were at very low or background levels (Fig. 8). Interestingly, each of two single point mutations, $\mathrm{C}_{62} \mathrm{G}$ and $\mathrm{G}_{72} \mathrm{C}$, resulted in a more severe splicing defect than the corresponding double mutation, $\mathrm{C}_{62} \mathrm{G} \mathrm{G}_{72} \mathrm{C}$, indicating that the structural integrity of the intramolecular $\mathrm{U} 6$ helix is very important for splicing activity. It may be surprising that the two double substitutions had such different effects on U4-U6 interaction (Fig. 6), with $\mathrm{C}_{63} \mathrm{G} \mathrm{G}_{71} \mathrm{C}$ having very low U4-U6 interaction activity and $\mathrm{C}_{62} \mathrm{G} \mathrm{G}_{72} \mathrm{C}$ behaving like wild-type. A likely explanation may be that the U4-U6 stability in the $\mathrm{C}_{63} \mathrm{G}$ $\mathrm{G}_{71} \mathrm{C}$ mutant is weaker than in the $\mathrm{C}_{62} \mathrm{G} \mathrm{G}_{72} \mathrm{C}$ mutant; in $\mathrm{C}_{63} \mathrm{G} \mathrm{G}_{71} \mathrm{C}$, the penultimate base pair of the U4-U6 stem II is eliminated and therefore is probably also the last one $\left(G_{72}\right.$ of $U 6$ and $C_{3}$ of U4). In contrast, for $C_{62} G$ $\mathrm{G}_{72} \mathrm{C}$, a destabilizing effect (by eliminating the last $\mathrm{G}-\mathrm{C}$ pair of the U4-U6 stem II) and a slight stabilization (by changing a $\mathrm{C}-\mathrm{U}$ mismatch to a $\mathrm{G}-\mathrm{U}$ pair) add up to a smaller destabilizing effect. The phenotypes of the two double mutations $\mathrm{C}_{62} \mathrm{G} \mathrm{G}_{72} \mathrm{C}$ and $\mathrm{C}_{63} \mathrm{G} \mathrm{G}_{71} \mathrm{C}$ demonstrate that small differences in the stability of the U4U6 helix can have dramatic effects on the efficiency of U4/U6 snRNP assembly. Taken together, five different point mutations destabilizing the $\mathrm{U} 6$ helix $\left(\mathrm{C}_{62} \mathrm{G}, \mathrm{C}_{63} \mathrm{G}\right.$, $\mathrm{G}_{71} \mathrm{C}, \mathrm{G}_{71} \mathrm{~A}$, and $\mathrm{G}_{72} \mathrm{C}$ ) all resulted in severe splicing defects, independent of whether they increased or decreased the stability of the U4-U6 helix; this makes it unlikely that these splicing defects are caused simply by blocking the U4-U6 dissociation in the spliceosome. Because the U4-U6 interaction and spliceosome assembly properties of these single-point mutants were unaffected, an intact U6 helix appears to be important for the first step of the splicing reaction. In sum, our data suggest that the balanced stability of different U6 RNA conformations is not only critical for the U4-U6 interaction but also during the splicing reaction.

\section{Discussion}

In the current model of the spliceosome cycle, U6 RNA is thought to undergo several conformational transitions: assembly of the U4 snRNP and U6 RNA/RNP into the U4-U6 snRNP; dissociation of the U4-U6 basepairing in the spliceosome and isomerization of the U4 U6 to the U6-U2 structure; after splicing, release of separate $\mathrm{U} 4$ and $\mathrm{U} 6$ from the spliceosome; recycling of $\mathrm{U} 4$ and $\mathrm{U} 6$ by reassembly into the U4/U6 snRNP /see introductory section for references). Secondary structure models for three different conformational states of U6 have been proposed and, in part, experimentally established: for the singular form of U6 (U6 RNP), for the U4-U6 base-paired form (U4/U6 snRNP), and for a U6U2 structure (see Fig. 9). Because the transition from the U4-U6 to the U6-U2 structure involves a major rearrangement in the spliceosome, there may be even more, transient conformational stages.

By use of a mutational approach and an in vitro splicing complementation system, we have investigated sequence requirements and conformational changes of U6 RNA during the mammalian spliceosome cycle. Previously, we have identified U6 sequences essential for spliceosome assembly and U4/U5/U6 multi-snRNP formation, focusing on the $5^{\prime}$-terminal, central, and the $3^{\prime}$ terminal domains (Wolff and Bindereif 1992). In an earlier interference and mutational study of U6 RNA sequence requirements, we had demonstrated that in the U4/U6 snRNP the U4 and U6 RNAs are base-paired through the entire stem I and stem II sequences (Bindereif et al. 1990). Because those earlier assays were done at high temperature and ionic strength $\left(42^{\circ} \mathrm{C}, 400 \mathrm{~mm}\right.$ $\mathrm{KCl}$, the formation of a stable U4/U6 snRNP required extensive perfect base-pairing. In contrast, in the present study we used splicing-compatible conditions $\left(30^{\circ} \mathrm{C}, 60\right.$ $\mathrm{mM} \mathrm{KCl}$ ).

Our initial interest concentrated on U4/U6 snRNP formation. Interestingly, assembly of affinity-purified 

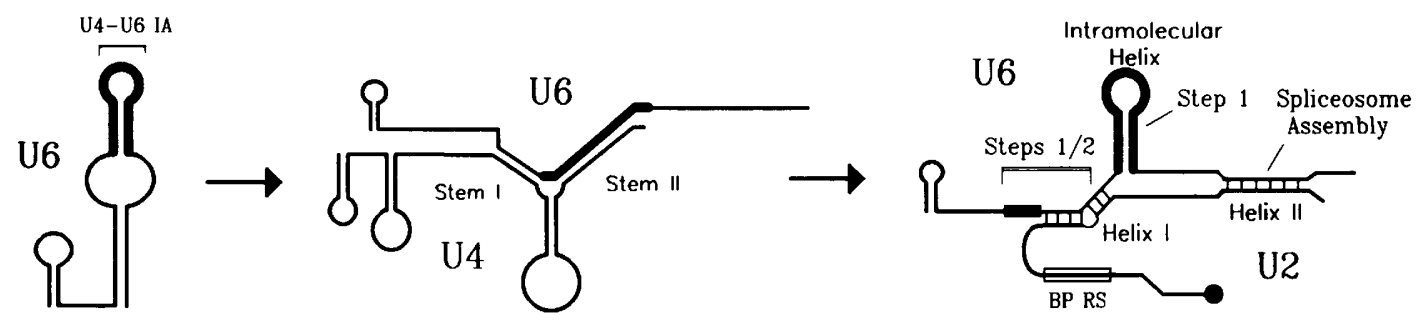

Figure 9. Schematic representation of U6 RNA conformations during the splicesome cycle: U6 singular form (Rinke et al. 1985); U4-U6 base-paired form (Guthrie and Patterson 1988); U6-U2 structure (Madhani and Guthrie 1992). Heavy lines highlight the U6 RNA region that can exist as an intramolecular stem-loop or base-paired with U4 as stem II. In the U6-U2 structure, the branchpoint recognition sequence (BP RS) of U2 is represented by an open box, the ACAGAGA sequence of U6 (nucleotides 41-47) by a solid box; the remainder of $\mathrm{U} 2$ is indicated by a solid circle. It is outlined in the U6-U2 structure where functional activities have been mapped: (1) U6-U2 helix II [splicing (Datta and Weiner 1991; Wu and Manley 1991); spliceosome assembly (Wolff and Bindereif 1992)]; (2) ACAGAGA box and adjacent U6-U2 helix I [first and second step of splicing (Fabrizio and Abelson 1990; Madhani and Guthrie 1992)]; (3) intramolecular U6 helix [first step of splicing (this study)].

U4 snRNP and U6 RNA into a stable complex occurred only in extract, suggesting that an additional protein factor is required. Our results indicate only that this protein is not contained within the core U4 snRNP; we do not know whether it associates with the U4 snRNP or with U6 RNA. In yeast, PRP24 has been implied to be a protein that binds transiently to U6 and mediates the U4U6 interaction (Shannon and Guthrie 1991). Therefore, it is possible that there exists a homologous protein with U4-U6 annealing activity in the mammalian system.

Through chemical modification/interference assays, the U6 nucleotides most important for U4-U6 interaction were identified: Significantly, five of these positions coincide with the 3'-terminal loop (nucleotides 65-69, $5^{\prime}$-GCGCA-3') in the proposed singular U6 structure (see Fig. 1). Additional interference effects were observed at the loop-closing $A_{70}$ and at nucleotides 53,55, and 56. Our interference data agree with results from internal deletions that the U6 stem II region, which makes up the intramolecular stem-loop in the singular U6 structure, is essential for U4-U6 interaction, whereas stem I plays an auxiliary role. Results from heterologous U4-U6 assays underlined the importance of the putative loop region for U4-U6 interaction: First, formation of a heterologous human U4/yeast U6 hybrid could be detected only after 2 nucleotides in the loop sequence of yeast U6 were changed to that in the corresponding human sequence $\left(\mathrm{A}_{73} \mathrm{G} \mathrm{U}_{74} \mathrm{C}\right)$. Second, trypanosome and human U6 RNAs are identical in the loop sequence, and the human/trypanosome hybrid U4/U6 snRNP was found to form efficiently.

After identifying the $3^{\prime}$-terminal loop of the singular U6 RNA as a major determinant of U4/U6 snRNP assembly, we asked what functional role the adjacent U6 helix plays and how the sequence of this region and the stability of the two U6 conformations (intramolecular stem-loop vs. U4-U6 stem II) influences U4/U6 snRNP assembly. To address these questions, single- and double-point mutations in the intramolecular U6 helix were analyzed, which should either stabilize or destabilize one of the two conformations. We found that the ability of U6 to interact with the U4 snRNP correlates well with the predicted stabilities of the singular U6 and the U4-U6 structures (see Table 1): First, stabilizing the intramolecular U6 helix strongly reduced U4-U6 interaction, whereas destabilizing mutations did not affect it; and second, U4/U6 snRNP assembly was severely reduced only by a strongly destabilized stem II base-pairing (see mutant $\mathrm{C}_{63} \mathrm{G} \mathrm{G}_{71} \mathrm{C}$ ). This suggests that a delicately balanced stability of the U6 conformations is critical for the opening of the intramolecular U6 helix and efficient U4-U6 interaction.

The data described above support the proposed intramolecular stem-loop structure (nucleotides 57-78) within the singular U6 RNA; the formation of this secondary structure element has also been suggested by an in vivo suppression analysis and chemical modification studies of yeast U6 (D. Fortner and D. Brow, pers. comm.) and by a phylogenetic covariation analysis (Guthrie and Patterson 1988; C. Guthrie, S. Mian, and H. Roiha, unpubl.). Moreover, our results led us to propose a model for how the U4-U6 interaction is initiated: The loop sequence of the 3'-terminal stem-loop structure of singular U6 would provide the first base-pairing contact between U6 RNA and the complementary sequence near the $5^{\prime}$ terminus of U4 RNA (nucleotides 6-10); starting from the center of the stem II region, base-pairing would then extend to the full stem I/stem II structure, possibly involving nucleation of stem I by nucleotides 53,55 , and 56. An initial RNA base-pairing contact between a loop and a linear sequence resembles known antisense RNA mechanisms such as the RNA-OUT/tnp mRNA interaction involved in translational control of Tn10 transposase expression (e.g., see Kittle et al. 1989). RNA-RNA interactions involving a loop sequence may be favored because a loop represents a particularly exposed target region or because of the stability of the resulting duplex (for review, see Eguchi et al. 1991). For efficient formation of a stable U4/U6 snRNP, intact 3'-terminal sequences are required in addition to the loop sequence; in contrast, the $5^{\prime}$-terminal and central domains are dispensable. Therefore, base-pairing between the $3^{\prime}$-termi- 
nal sequences and the central domain as proposed in the singular U6 structure (see Fig. 1) is not essential for U4/ U6 snRNP assembly. In sum, the $3^{\prime}$-terminal stem-loop (nucleotides 57-78) of the singular U6 form, although not sufficient, is a major determinant of U4-U6 interaction.

To search for a potential function of the intramolecular U6 helix beyond U4-U6 interaction, we assayed the U6 point mutants for their spliceosome assembly and splicing activities (see Table 1). Mutations stabilizing the intramolecular U6 helix resulted in very low or undetectable activities, most likely because these mutants were defective in U4-U6 interaction. To our surprise, however, we found that five different destabilizing $\mathrm{mu}$ tations at positions $\mathrm{C}_{62}, \mathrm{C}_{63}, \mathrm{G}_{71}$, and $\mathrm{G}_{72}$ all resulted in a severe splicing defect $(<10 \%$ of wild-type activity), even though U4/U6 and spliceosome assembly was normal, demonstrating that each of these positions is splicing essential and specifically required for the first step of splicing. Previous studies found that the functionality of U6 RNA in splicing always correlated with spliceosome formation (Fabrizio and Abelson 1990; Vankan et al. 1992; Wolff and Bindereif 1992). The mutant U6 RNAs described in this study represent the first examples that are defective in the first step of splicing, yet assemble efficiently into stable spliceosomes; a similar phenotype has been reported only for two yeast $U 2$ point mutations in helix I of the U6-U2 interaction region (McPheeters and Abelson 1992).

How can the splicing defects of the mutants with a destabilized U6 helix be explained? Some of these mutations are expected to stabilize and others to destabilize the U4-U6 base-pairing in stem II, making the interpretation unlikely that U4-U6 dissociation in the spliceosome might be blocked. All of the observed splicing defects may be related to the destabilizing effect of the mutations on the intramolecular $\mathrm{U} 6$ helix. A double mutation inverting the $\mathrm{C}_{62}-\mathrm{G}_{72}$ base pair should have only little effect on the stability of the U6 helix, in contrast to the two corresponding single-point mutations. Because the compensatory double-point mutation had a less severe effect on splicing than the two single-point mutations, at least in this position the base-paired structure appears to be important. The absolute conservation of the sequence of the upper $3 \mathrm{bp}$ of the helix, however, also argues for the importance of base identity at these positions. Further support for a splicing function of the intramolecular U6 helix comes from our previous mutational analysis, where we determined that deleting nucleotides $77-79$ at the bottom of the helix partially blocked the second step of splicing (Wolff and Bindereif 1992). The essential function of U6 stem II nucleotides in the first step of splicing might also be reflected in the asymmetric conservation of the U4-U6 hybrid: U6 positions are more conserved than the corresponding $U 4$ nucleotides, arguing for an additional function beyond U4-U6 base-pairing (Guthrie and Patterson 1988). The splicing function of the U6 stem II region has been analyzed previously in two other systems. In yeast, a number of mutations in this region have been tested for splic- ing in vivo (Madhani et al. 1990; Shannon and Guthrie 1991) and in vitro (Fabrizio and Abelson 1992). Surprisingly, there are several single-nucleotide deletions and substitutions, even at the conserved positions, that did not affect splicing. Deletion of the conserved $A_{75}$ or $G_{77}$ of yeast U6 RNA (see Fig. 3C), however, had a lethal phenotype (Madhani et al. 1990). The yeast $U_{80} G$ mutation resulted in a block of U4/U6 snRNP assembly both in vitro and in vivo, possibly as a result of the hyperstabilization of the U6 helix (Madhani et al. 1990; Fabrizio and Abelson 1992). Our results agree with and extend previous findings in the Xenopus system: Block substitutions within stem II of $\mathrm{U} 6$ abolished splicing activity; and compensatory U4 changes restored U4-U6 interaction, but not splicing (Vankan et al. 1990). Some of the discrepancies between the results from our mammalian in vitro splicing system and the analyses in yeast are probably the result of differences between the assay systems (in vitro vs. in vivo); for example, a particular step of the spliceosome cycle may be rate limiting only under certain conditions. In addition, there may also be species-specific differences; for example, although the upper part of the U6 helix is absolutely conserved, the lower part appears to be less stable in the mammalian system than in yeast where a perfect helix of $4 \mathrm{bp}$ can be formed. This may contribute to the overall stability of the helix and explain why in yeast the splicing mechanism tolerates a number of mutations in this region.

In sum, on the basis of interference and mutational analyses, we have demonstrated that the intramolecular stem-loop region of $U 6$ (nucleotides 57-78) functions at two stages of the spliceosome cycle: first, in U4/U6 snRNP assembly, where we have proposed that the loop portion acts early as a U4 recognition loop; and second, during the first step of splicing. How do our results relate to the U6-U2 structure, which has recently been proposed to be directly involved in the catalytic activation of the spliceosome (Madhani and Guthrie 1992)? It has not been known whether the three elements of this structure, the U6-U2 pairing at the U6 $3^{\prime}$ end (helix II), the U6-U2 helix I, and the intramolecular U6 helix in between, coexist within the spliceosome. There is very good genetic evidence for an essential role of the two U6-U2 base-pairing interactions in splicing (in yeast and mammals, respectively|. Because we have demonstrated a specific splicing function of the intramolecular U6 helix region, it now appears more plausible and attractive that this structural element actually forms and functions in the context of the U6-U2 structure. Significantly, an intron insertion has been found in the Rhodotorula hasegawae U6 RNA gene that maps between two conserved positions in the intramolecular helix (corresponding to $G_{72}$ and $A_{73}$ of the human U6 RNA) (Tani and Ohshima 1991). The function of helix II might be to stabilize the catalytic core structure. The highly conserved ACAGAGA sequence adjoining the U6-U2 helix I has been identified as another element of U6 essential for both the first and second step of splicing (Fabrizio and Abelson 1990; T. Wolff, R. Menssen, J. Hammel, and A. Bindereif, in prep.). In the spliceosome, the 
ACAGAGA sequence, the two U6-U2 helices, and the U6 intramolecular helix together may form an extended catalytic core that exists during both the first and second step of splicing.

An important open question remains how the intramolecular U6 helix functions in splicing - whether by interacting with spliceosomal proteins or other snRNAs, or as a catalytic RNA component of the splicing machinery. The existence of the intramolecular U6 stem-loop in the splicesome raises the possibility that this structure persists throughout splicing and spliceosome disassembly; U6 may be released in a form base-paired with $\mathrm{U} 2$ or in the singular form; in either case, the $3^{\prime}$-terminal loop might serve to initiate the subsequent reassembly of the U4/U6 snRNP to participate in the next splicing cycle. The model for the de novo U4/U6 snRNP assembly proposed above may therefore also apply to U4/U6 recycling.

\section{Materials and methods}

DNA oligonucleotides

The sequence of oligonucleotide 2638 is $5^{\prime}$-GCGGATCCTTTAAAAATATGGAACGCTTCACG-3'; that of 2639 is 5'-GCGAATTCTAATACGACTCACTATAGTGCTCGCTTCGGCAGC-3'.

\section{Mutagenesis, in vitro transcription, and $3^{\prime}$-end-labeling}

T7-U6 was constructed by amplifying the U6-coding sequence with PCR methods with SP6-U6 (Bindereif et al. 1990) as a template and oligonucleotides 2638 and 2639 as primers. The amplified fragment was digested with EcoRI and BamHI and subcloned in pUC19. The following mutant derivatives of T7U6 were generated by PCR methods, using T7-U6 as template and oligonucleotides carrying the respective substitutions, followed by subcloning in pUC19: T7-U6 $\mathrm{C}_{62} \mathrm{G}$; T7-U6 $\mathrm{C}_{63} \mathrm{G}$; T7-U6 G G $_{71} \mathrm{~A}_{;}$T7-U6 G $\mathrm{G}_{71} \mathrm{C}_{;}$T7-U6 $\mathrm{G}_{72} \mathrm{C}$; T7-U6 A $\mathrm{A}_{73} \mathrm{G} ;$ T7-U6 $\mathrm{C}_{62} \mathrm{G} \mathrm{G}_{71} \mathrm{~A}_{;}$T7-U6 $\mathrm{C}_{62} \mathrm{G} \mathrm{G}_{72} \mathrm{C}$; T7-U6 $\mathrm{C}_{63} \mathrm{G} \mathrm{G}_{71} \mathrm{C} ; \mathrm{T} 7-\mathrm{U} 6$ $\mathrm{A}_{73} \mathrm{G} \Delta \mathrm{U}_{74} ; \mathrm{T} 7-\mathrm{U} 6 \mathrm{~A}_{73} \mathrm{G} \Delta \mathrm{U}_{74} \mathrm{~A}_{76} \mathrm{C}$. The yeast derivative T7YU6 $\mathrm{A}_{73} \mathrm{G} \mathrm{U}_{74} \mathrm{C}$ was generated by PCR methods from T7-YU6 template and a mutagenic oligonucleotide. All of the plasmids described above were linearized with DraI before in vitro transcription with T7 RNA polymerase. The plasmid T7-TbU6 encoding the trypanosomal U6 sequence (Cross et al. 1991) was linearized with $X b a I$.

The plasmids SP6-U6, SP6-U6 $5^{\prime} \Delta 37$, SP6-U6 $5^{\prime} \Delta 52$, SP6U6 $3^{\prime} \Delta 20$, and SP6-U6 $3^{\prime} \Delta 44$ have been described previously (Bindereif et al. 1990), as well as the plasmids SP6-U6 $\Delta$ P28 $(\Delta 49-56)$, SP6-U6 $\Delta \mathrm{P} 20(\Delta 57-65)$, and SP6-U6 $\Delta \mathrm{P} 11(\Delta 66-74)$, which were renamed in this study SP6-U6 $\Delta$ StemI, SP6-U6 $\Delta$ StemIIa, and SP6-U6 $\Delta$ StemIIb, respectively. The plasmids SP6-U6 $\Delta 18-21$, SP6-U6 $\Delta 74-76$, SP6-U6 $\Delta 77-79$, SP6-U6 $\Delta 80-82$, SP6-U6 $\Delta 83-85$, SP6-U6 $\Delta 86-89$, SP6-U6 $\Delta 90-92$, SP6-U6 $\Delta 96-98$, and SPG-U6 $\Delta 99-101$ are described in Wolff and Bindereif (1992). All SP6-U6 derivatives were linearized with BamHI before in vitro transcription with SP6 RNA polymerase.

U6 RNA derivatives were transcribed in the presence of GpppG cap analog by SP6 or T7 RNA polymerase as described (Bindereif and Green 1987); MINX pre-mRNA (Zillmann et al. 1987) was transcribed by SP6 RNA polymerase in the presence of $\mathrm{m}^{7}$ GpppG. All SP6-U6 RNAs carry an additional GGA at their $5^{\prime}$ ends and a CG(GAUC) at their $3^{\prime}$ ends, depending on whether the BamHI runoff site is transcribed through. In contrast, the T7-U6 RNAs derived from the human U6 RNA have no additional nucleotides at their $5^{\prime}$ and $3^{\prime}$ ends. T7-U6 RNAs were labeled at the $3^{\prime}$ end with $\left[{ }^{32} \mathrm{P} \mid \mathrm{pCp}\right.$ and T4 RNA ligase, as described (England et al. 1980).

\section{Analysis of U4-U6 interaction by anti-Sm immunoprecipitation}

The interaction of U6 RNA with the U4 snRNP was determined by anti-Sm immunoprecipitation of ${ }^{32} \mathrm{P}$-labeled synthetic U6 RNAs reconstituted into U4/U6 snRNPs. SP6-U6 RNAs were used uniformly labeled with $\left[{ }^{32} \mathrm{P} \mid \mathrm{UTP}\right.$, whereas T7-U6 RNAs were labeled at their 3 ' ends with ${ }^{32} \mathrm{P}$-labeled $\mathrm{pCp}$ and T4 RNA ligase (England et al. 1980). U4/U6 snRNP-depleted nuclear extract and affinity-purified U4 snRNP were prepared as described (Wolff and Bindereif 1992). In a standard U4/U6 snRNP reconstitution, $10 \mathrm{ng}$ of ${ }^{32} \mathrm{P}$-labeled U6 RNA /or equimolar amounts of mutant derivatives) was incubated with $4 \mu \mathrm{l}$ of affinity-purified U4 snRNP for $15 \mathrm{~min}$ at $30^{\circ} \mathrm{C}$ in a $25-\mu$ l volume containing $7.5 \mu \mathrm{l}$ of U4/U6-depleted nuclear extract, $3.5 \mu \mathrm{l}$ of buffer D (Dignam et al. 1983), $3.2 \mathrm{~mm} \mathrm{MgCl}_{2}, 0.5 \mathrm{~mm}$ ATP, $20 \mathrm{~mm}$ creatine phosphate, $1600 \mathrm{U} / \mathrm{ml}$ of RNasin (Promega), and $40 \mu \mathrm{g} / \mathrm{ml}$ of yeast tRNA. After removing $10 \%$ of the reaction mixture for total RNA analysis, the remainder was incubated for $2 \mathrm{hr}$ at $4^{\circ} \mathrm{C}$ with $25 \mu$ l of protein A-Sepharose (Pharmacia) precoated with $2.5 \mu \mathrm{l}$ of anti-Sm serum in $750 \mu \mathrm{l}$ of NET- 500 buffer $(50 \mathrm{~mm}$ Tris/ $\mathrm{HCl}$ at $\mathrm{pH} 8.0,500 \mathrm{~mm} \mathrm{KCl}, 0.01 \% \mathrm{NP}-40$ ). The beads were washed three times with NET-500 buffer, and immunoprecipitated RNAs were recovered by phenol extraction and ethanol precipitation. The purified RNAs were analyzed by denaturing gel electrophoresis.

\section{Modification/interference analysis of U4/U6 snRNP assembly}

SP6-U6 RNA was $3^{\prime}$-end-labeled by $\left[^{32} \mathrm{P}\right] \mathrm{pCp}$ and T4 RNA ligase, gel-purified, and chemically modified at the purine and pyrimidine residues with DEPC (Sigma) and hydrazine (Serva), respectively, as described (Peattie 1979). Modified SP6-U6 RNA was assembled into U4/U6 snRNPs by incubation with affinitypurified U4 snRNP in U4/U6-depleted nuclear extract as described above. Modified SP6-U6 RNA incorporated in U4/U6 snRNPs was purified by anti-Sm immunoprecipitation and phenol extraction. RNA prepared from the immunoprecipitate and total modified SP6-U6 RNA was then cleaved at the sites of modification with aniline (Peattie 1979) and analyzed by denaturing gel electrophoresis.

\section{Splicing complementation and spliceosome assembly of U6 RNA}

The standard conditions of the two assays have been described previously in detail (Wolff and Bindereif 1992). To test for splicing complementation, the standard $25-\mu \mathrm{l}$-reaction contained $250 \mathrm{ng}$ of T7-U6 RNA and $1 \mathrm{ng}$ of uniformly ${ }^{32} \mathrm{P}$-labeled MINX pre-mRNA. In the spliceosome assembly assay, $20 \mathrm{ng}$ of 3 ' endlabeled T7-U6 and $75 \mathrm{ng}$ of unlabeled MINX RNA were used. In brief, T7-U6 RNAs were preincubated with $2 \mu \mathrm{l}$ of affinitypurified U4 snRNP in U4/U6-depleted nuclear extract under splicing conditions for $15 \mathrm{~min}$ at $30^{\circ} \mathrm{C}$ to allow U4/U6 snRNP reconstitution. After the addition of MINX pre-mRNA, incubation was continued as indicated. In the splicing complementation assay, the splicing products were subsequently isolated and analyzed by denaturing gel electrophoresis. To test for assembly 
of spliceosomes, the reactions were treated with heparin $(1 \mathrm{mg} /$ $\mathrm{ml}$ ) and analyzed by electrophoresis on native acrylamide-agarose RNP gels (Nelson and Green 1988).

\section{Acknowledgments}

We acknowledge the excellent technical assistance of Björn Wieland, Manuela Staeber, and Heike Roscher. We thank Mike Hearne for help with the oligonucleotide synthesis, Brian Sproat for advice on 2'-OMe RNA synthesis, Christine Guthrie, Hiten Madhani, and Joan Steitz for unpublished information, and Mike Cross for critical comments on the manuscript. This work was supported by the Deutsche Forschungsgemeinschaft (SFB $344 / \mathrm{C} 5)$.

The publication costs of this article were defrayed in part by payment of page charges. This article must therefore be hereby marked "advertisement" in accordance with 18 USC section 1734 solely to indicate this fact.

\section{References}

Behrens, S.-E. and R. Lührmann. 1991. Immunoaffinity purification of a [U4/U6.U5] tri-snRNP from human cells. Genes \& Dev. 5: 1439-1452.

Bindereif, A. and M.R. Green. 1987. An ordered pathway of snRNP binding during mammalian pre-mRNA splicing complex assembly. EMBO J. 6: 2415-2424.

Bindereif, A., T. Wolff, and M.R. Green. 1990. Discrete domains of human U6 snRNA required for the assembly of U4/U6 snRNP and splicing complexes. EMBO J. 9: 251-255.

Brow, D.A. and C. Guthrie. 1988. Spliceosomal RNA U6 is remarkably conserved from yeast to mammals. Nature 334: 213-218.

Cheng, S.-C. and J. Abelson. 1987. Spliceosome assembly in yeast. Genes \& Dev. 1: 1014-1027.

Conway, L. and M. Wickens. 1989. Modification interference analysis of reactions using RNA substrates. Methods Enzymol. 180: 369-379.

Cross, M., A. Günzl, Z. Palfi, and A. Bindereif. 1991. Analysis of small nuclear ribonucleoproteins (RNPs) in Trypanosoma brucei: Structural organization and protein components of the spliced leader RNP. Mol. Cell. Biol. 11: 5516-5526.

Datta, B. and A.M. Weiner. 1991. Genetic evidence for base pairing between $U 2$ and U6 snRNAs in mammalian mRNA splicing. Nature 352: 821-824.

Dignam, D.L., R.M. Lebovitz, and R.D. Roeder. 1983. Accurate transcription initiation by RNA polymerase II in a soluble extract from isolated mammalian nuclei. Nucleic Acids Res. 11: 1475-1489.

Eguchi, Y., T. Itoh, and J. Tomizawa. 1991. Antisense RNA. Annu. Rev. Biochem. 60: 631-652.

England, T.E., A.G. Bruce, and O.C. Uhlenbeck. 1980. Specific labeling of 3 '-termini of RNA with T4 RNA ligase. Methods Enzymol. 65: 65-74.

Fabrizio, P. and J. Abelson. 1990. Two domains of yeast U6 small nuclear RNA required for both steps of nuclear precursor messenger RNA splicing. Science 250: 404-409.

- 1992. Thiophosphates in yeast U6 snRNA specifically affect pre-mRNA splicing in vitro. Nucleic Acids Res. 20: 3659-3664.

Green, M.R. 1991. Biochemical mechanisms of constitution and regulated pre-mRNA splicing. Annu. Rev. Cell Biol. 7: 559-599.

Gröning, K., Z. Palfi, S. Gupta, M. Cross, T. Wolff, and A. Bindereif. 1991. A new U6 small nuclear ribonucleoprotein-spe- cific protein conserved between cis- and trans-splicing systems. Mol. Cell. Biol. 11: 2026-2034.

Guthrie, C. 1991. Messenger RNA splicing in yeast: Clues to why the spliceosome is a ribonucleoprotein. Science 253: 157-163.

Guthrie, C. and B. Patterson. 1988. Spliceosomal snRNAs. Annu. Rev. Gen. 23: 387-419.

Hamm, J. and I.W. Mattaj. 1989. An abundant U6 snRNP found in germ cells and embryos of Xenopus laevis. EMBO $J$. 8: $4179-4187$.

Harada, F., N. Kato, and S. Nishimura. 1980. The nucleotide sequences of nuclear $4.8 \mathrm{~S}$ RNA of mouse cells. Biochem. Biophys. Res. Comm. 95: 1332-1340.

Hausner, T.-P., L.M. Giglio, and A.M. Weiner. 1990. Evidence for base-pairing between mammalian U2 and U6 small nuclear ribonucleoprotein particles. Genes \& Dev. 4: 21462156.

Kittle, J.D., R.W. Simons, J. Lee, and N. Kleckner. 1989. Insertion sequence IS10 anti-sense pairing initiates by an interaction between the $5^{\prime}$ end of the target RNA and a loop in the anti-sense RNA. I. Mol. Biol. 210: 561-572.

Konarska, M.M. and P.A. Sharp. 1987. Interactions between small ribonucleoprotein particles in formation of spliceosomes. Cell 49: 763-774.

Madhani, H.D. and C. Guthrie. 1992. A novel base-pairing interaction between U2 and U6 snRNAs suggests a mechanism for the catalytic activation of the spliceosome. Cell 71: 803-817.

Madhani, H.D., R. Bordonné, and C. Guthrie. 1990. Multiple roles for U6 snRNA in the splicing pathway. Genes \& Dev. 4: 2264-2277.

Maniatis, T. and R. Reed. 1987. The role of small nuclear ribonucleoprotein particles in pre-mRNA splicing. Nature 325: 673-678

McPheeters, D.S. and J. Abelson. 1992. Mutational analysis of the yeast U2 snRNA suggests a structural similarity to the catalytic core of group I introns. Cell 71: 819-831.

Myslinski, E. and C. Branlant. 1991. A phylogenetic study of U4 snRNA reveals the existence of an evolutionarily conserved secondary structure corresponding to "free" U4 snRNA. Biochimie 73: 17-28.

Nelson, K.K. and M.R. Green. 1988. Splice site selection and ribonucleoprotein complex assembly during in vitro premRNA splicing. Genes \& Dev. 2: 319-329.

Peattie, D.A. 1979. Direct chemical method for sequencing RNA. Proc. Natl. Acad. Sci. 76: 1760-1764.

Pikielny, C.W., B.C. Rymond, and M. Rosbash. 1986. Electrophoresis of ribonucleoproteins reveals an ordered assembly pathway of yeast splicing complexes. Nature 324: 341-345.

Rinke, J., B. Appel, M. Digweed, and R. Lührmann. 1985. Localization of a base-paired interaction between small nuclear RNAs U4 and U6 in intact U4/U6 ribonucleoprotein particles by psoralen cross-linking. I. Mol. Biol. 185: 721-731.

Sawa, H. and Y. Shimura. 1992. Association of U6 snRNA with the $5^{\prime}$-splice site region of pre-mRNA in the spliceosome. Genes \& Dev. 6: 244-254.

Shannon, K.W. and C. Guthrie. 1991. Suppressors of a U4 snRNA mutation define a novel U6 snRNP protein with RNAbinding motifs. Genes \& Dev. 5: 773-785.

Singh, R., J. Gupta, and R. Reddy. 1990. Capping of mammalian U6 small nuclear RNA in vitro is directed by a conserved stem-loop and AUAUAC sequence: Conversion of a noncapped RNA into a capped RNA. Mol. Cell. Biol. 10: 939946.

Steitz, J.A. 1992. Splicing takes a Holliday. Science 257: 888889. 
Steitz, J.A., D.L. Black, V. Gerke, K.A. Parker, A. Kramer, D. Frendewey, and W. Keller. 1988. Functions of the abundant U-snRNPs. In Structure and function of major and minor small nuclear ribonucleoprotein particles (ed. M.L. Birnstiel), pp. 115-154. Springer-Verlag, Berlin, Germany.

Tani, T. and Y. Ohshima. 1991. mRNA-type introns in U6 small nuclear RNA genes: Implications for the catalysis in premRNA splicing. Genes \& Dev. 5: 1022-1031.

Vankan, P., C. McGuigan, and I.W. Mattaj. 1990. Domains of U4 and U6 snRNAs required for snRNP assembly and splicing complementation in Xenopus oocytes. EMBO I. 9: 33973404.

Vankan, P., C. McGuigan, and I.W. Mattaj. 1992. Roles of U4 and U6 snRNAs in the assembly of splicing complexes. EMBO I. 11: 335-343.

Wassarman, D.A. and J.A. Steitz. 1992. Interactions of small nuclear RNAs with precursor messenger RNA during in vitro splicing. Science 257: 1918-1925.

Watkins, K.-P. and N. Agabian. 1991. In vivo UV cross-linking of $U$ snRNAs that participate in trypanosome trans-splicing. Genes \& Dev. 5: 1859-1869.

Weiner, A.M. 1993. mRNA splicing and autocatalytic introns: Distant cousins or the products of chemical determinism? Cell 72: 161-164.

Wersig, C. and A. Bindereif. 1992. Reconstitution of functional mammalian U4 small nuclear ribonucleoprotein: Sm protein binding is not essential for splicing in vitro. Mol. Cell. Biol. 12: 1460-1468.

Wolff, T. and A. Bindereif. 1992. Reconstituted mammalian U4/ U6 snRNP complements splicing: A mutational analysis. EMBO I. 11: 345-359.

Wu, J.A. and J.L. Manley. 1991. Base-pairing between U2 and U6 snRNAs is necessary for splicing of a mammalian premRNA. Nature 352: 818-821.

1992. Multiple functional domains of human U2 small nuclear RNA: Strengthening conserved stem I can block splicing. Mol. Cell. Biol. 12: 5464-5473.

Wyatt, J.R., E.J. Sontheimer, and J.A. Steitz. 1992. Site-specific cross-linking of mammalian U5 snRNP to the $5^{\prime}$ splice site before the first step of pre-mRNA splicing. Genes \& Dev. 6: $2542-2553$.

Yean, S.-L. and R.-J. Lin. 1991. U4 small nuclear RNA dissociates from a yeast spliceosome and does not participate in the subsequent splicing reaction. Mol. Cell. Biol. 11: 5571-5577.

Zillmann, M., M.L. Zapp, and S.M. Berget. 1988. Gel electrophoretic isolation of splicing complexes containing U1 small nuclear ribonucleoprotein particles. Mol. Cell. Biol. 8: 814 821. 


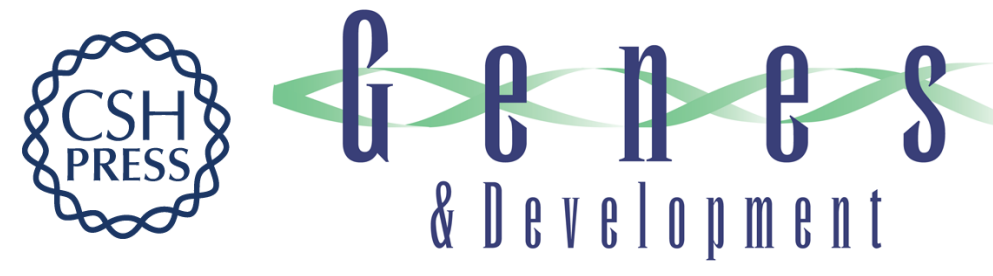

\section{Conformational changes of U6 RNA during the spliceosome cycle: an intramolecular helix is essential both for initiating the U4-U6 interaction and for the first step of slicing.}

T Wolff and A Bindereif

Genes Dev. 1993, 7:

Access the most recent version at doi:10.1101/gad.7.7b.1377

References This article cites 48 articles, 22 of which can be accessed free at:

http://genesdev.cshlp.org/content/7/7b/1377.full.html\#ref-list-1

License

Email Alerting

Receive free email alerts when new articles cite this article - sign up in the box at the

Service top right corner of the article or click here.

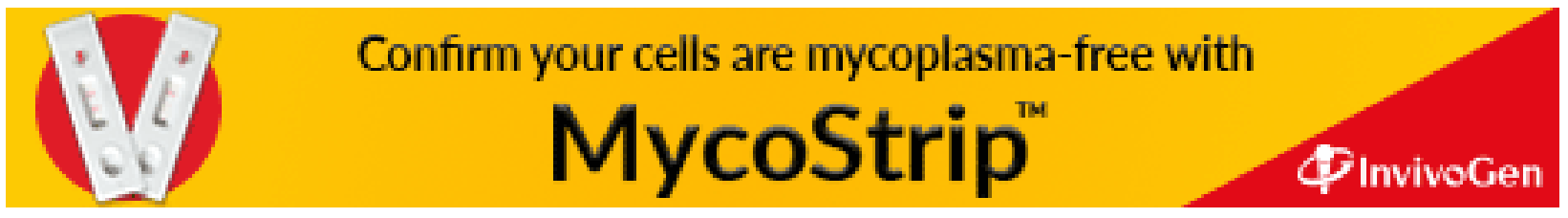

